\title{
STATISTICS BELIEFS OF ADVANCED SOCIAL SCIENCE STUDENTS - A QUALITATIVE EVALUATION OF FOCUS GROUPS
}

\author{
Florian Berens \\ University of Goettingen, Germany \\ florian.berens@uni-gotettingen.de
}

Unlike mathematics education, statistics education has given little attention to students' beliefs. In comparison it is possible that statistics may open up another domain-specific horizon of possible beliefs. However, there is no explicit theory about beliefs on statistics. In order to gain insight into students' beliefs about statistics, focus groups of advanced social science students were conducted. The focus groups were analyzed by content analysis and then partly by hermeneutics in order to identify types of beliefs. As a result well-known belief systems from mathematics can also be found in statistics. There are students who view statistics as a system of terms and rules, and there are also students who understand statistics dynamically. The last group can be subdivided into those that extract information out of data and those that want to check theory using data. A fourth group sees statistics as a form of systematic description of reality. 